\title{
The Concentration of the 35-kDa Surfactant Apoprotein in Amniotic Fluid from Normal and Diabetic Pregnancies
}

\author{
JEANNE M. SNYDER, JEANINE E. KWUN, JEAN A. O'BRIEN, CHARLES R. ROSENFELD, AND \\ M. JANELLE ODOM \\ The Cecil H. and Ida Green Center for Reproductive Biology Sciences and the Departments of Cell Biology and \\ Anatomy, Obstetrics-Gynecology, and Pediatrics, University of Texas Southwestern Medical Center at Dallas,
} Dallas, Texas 75235

\begin{abstract}
A specific, enzyme-linked immunoabsorbent assay was used to determine the concentration of the $35,000 \mathrm{~mol}$ wt surfactant apoprotein (SP-A) in samples of amniotic fluid obtained from nondiabetic $(n=358)$ and diabetic $(n=29)$ women. The enzyme-linked immunoabsorbent assay was performed with rabbit antibodies directed against SP-A present in lavage fluid from a patient with alveolar proteinosis. Amniotic fluid SP-A concentrations increased as a function of gestational age, from $<3$ $\mu \mathrm{g} / \mathrm{ml}$ at 30-31 wk to $24 \mu \mathrm{g} / \mathrm{ml}$ at $40-41 \mathrm{wk}$, and were positively correlated with the lecithin to sphingomyelin ratio $(p<0.01)$. SP-A concentrations also increased as a function of gestational age in shake test positive samples $(p<0.05)$, but were unchanged in shake test-negative samples. There was no difference in the surfactant apoprotein concentration of male compared with female fetuses at any gestational age. In amniotic fluid obtained from 20 diabetic women, SP-A levels were significantly less than in nondiabetic pregnancies that were matched for gestational age and sex of the fetus $(p<0.05)$. The SP-A concentrations in amniotic fluids obtained from nine women who were diabetic and hypertensive and from 10 hypertensive women were not different from matched controls. The relationships described above were valid whether the SPA concentration was expressed per $\mathrm{mg}$ protein or per $\mathrm{ml}$ amniotic fluid. These data are suggestive that the concentration of amniotic fluid SP-A is decreased in diabetic pregnancies. (Pediatr Res 24: 728-734, 1988)
\end{abstract}

\section{Abbreviations}

RDS, respiratory distress syndrome SP, surfactant apoprotein $\mathrm{L} / \mathrm{S}$, lecithin to sphingomyelin ratio ELISA, enzyme-linked immunoabsorbent assay PBS, phosphate-buffered saline ANOVA, analysis of variance

The leading cause of death in preterm neonates is RDS, a disorder that is caused by an immaturity in the synthesis and secretion of surfactant by the fetal lung type II cell (1). Surfactant

Received April 11, 1988; accepted August 12, 1988.

Correspondence and requests for reprints to Jeanne M. Snyder, Ph.D., Department of Anatomy, The University of Iowa College of Medicine, Iowa City, IA 52242 .

Supported in part by National Institutes of Health Grant HD13912 and by Clinical Research Grant 6-365 from the March of Dimes Birth Defects Foundation. is comprised of both phospholipid $(\sim 80 \%)$ and protein $(\sim 10 \%)$ components (2). The concentration of surfactant phospholipid, in particular dipalmitoylphosphatidylcholine, increases in amniotic fluid as a function of gestational age (3). The most commonly used means of assessing fetal lung maturation is the determination of the $\mathrm{L} / \mathrm{S}$ ratio, an index of the amniotic fluid concentration of surfactant-derived saturated phosphatidylcholine relative to sphingomyelin, a phospholipid whose concentration in amniotic fluid does not change as a function of gestational age (4). Several investigators have reported that the concentration of the $35,000 \mathrm{~mol}$ wt SP-A in amniotic fluid increases as a function of gestational age, similar to the increase in surfactant phospholipid (5-9). Recently, low mol wt, hydrophobic SP-B and SP-C have been described $(10,11)$. In contrast to SP-A, the fetal lung and amniotic fluid concentrations of the low mol wt, hydrophobic surfactant apoproteins apparently increase several weeks before the commencement of augmented surfactant secretion by the fetal lung $(12,13)$.

The fetuses of women with diabetes (at least those in which the diabetes is not carefully controlled) are known to have an increased risk of developing RDS at birth (14). Several investigators have found that the $\mathrm{L} / \mathrm{S}$ ratio is not a reliable predictor of lung maturation in pregnancies complicated by diabetes $(15,16)$. Because the fetus of the diabetic mother is known to be hyperinsulinemic, it has been proposed that the deleterious effects of maternal diabetes on the fetus are due to elevated fetal plasma insulin levels $(17,18)$. In previous studies, we have shown that insulin, when added alone to serum-free medium, has no effect on surfactant phospholipid synthesis by human fetal lung tissue maintained in vitro $(19,20)$. In a more recent study, however, we have shown that insulin does inhibit the accumulation of SP$A$ in human fetal lung tissue maintained in vitro (21). Thus, we postulate that the infant of the diabetic mother may have an increased risk of developing RDS because its surfactant is deficient in SP-A relative to phospholipids. It has been shown that SP-A, acting alone or in concert with the low mol wt, hydrophobid surfactant apoproteins, facilitates the spreading of surfactant phospholipids at an air-water interface $(22,23)$.

To test this hypothesis further, we determined the concentration of SP-A in amniotic fluid samples obtained from 358 nondiabetic pregnancies and from 29 diabetic pregnancies. Our results are suggestive that the surfactant produced by the infant of the diabetic mother is characterized by a decreased concentration of SP-A.

\section{MATERIALS AND METHODS}

Preparation of antibodies directed against the 35,000 mol wt $S P-A$. SP-A was present in high concentration in lavage fluid obtained from a patient treated for alveolar proteinosis (24). This 
material, which was not purified further, was used to immunize rabbits to raise polyclonal antibodies directed against SP-A. The serum obtained from the immunized rabbit was preabsorbed overnight with human serum in order to remove antibodies directed against serum proteins. The preabsorbed antiserum was centrifuged at $12,000 \times g$ for $10 \mathrm{~min}$ before use. To validate the use of this antibody for measurement of the surfactant apoprotein in amniotic fluid, an immunoblot of term amniotic fluid proteins, separated by 2-dimensional gel electrophoresis, was performed using the preabsorbed rabbit antiserum as the source of primary antibody $(21,25)$.

Description of the assay for the 35,000 mol wt $S P$ - $A$. An ELISA was used to quantify SP-A in amniotic fluid samples. Antigencoated, 96-well microtiter plates (Nunc Immuno Plate II F, Roskilde, Denmark) were prepared by incubating each well with $200 \mu \mathrm{l}$ of coating buffer $(0.1 \mathrm{M} \mathrm{Na}$ carbonate, $\mathrm{pH} 9.6)$ that contained $100 \mathrm{ng}$ purified surfactant apoprotein. The plate was incubated overnight at $4^{\circ} \mathrm{C}$ to facilitate adherence of the surfactant apoprotein to the bottom of the well. The surfactant apoprotein used to coat the dishes and used for standards was purified from alveolar proteinosis material by delipidation, followed by Affigel blue chromatography, as described by the manufacturer (BioRad, San Mateo, CA), to remove serum proteins. Protein concentrations of the SP-A standards and amniotic fluid samples was determined by the method of Lowry et al. (26).

A second plate was used to incubate the SP-A standards and amniotic fluid samples with the rabbit antiserum directed against SP-A. All standards and samples were diluted in PBS-Tween buffer $\left[\mathrm{NaCl}(0.14 \mathrm{M}), \mathrm{PO}_{4}(0.1 \mathrm{M})\right.$, Tween-20 $(0.005 \%)$, pH 7.2] and were assayed in triplicate. The standard curve ranged from $1 \mathrm{ng} / \mathrm{ml}$ to $10 \mu \mathrm{g} / \mathrm{ml}$. The amniotic fluid samples were diluted to two different protein concentrations, generally 25 and $50 \mu \mathrm{g}$ total protein $/ \mathrm{ml}$. The samples and standards were added to the wells in a volume of $150 \mu \mathrm{l}$. An equal volume of the rabbit antibody directed against surfactant apoprotein was added to each well. The final dilution of the antibody was 1:5,000. The plate that contained the amniotic fluid samples and standards plus primary antibody was incubated overnight at $4^{\circ} \mathrm{C}$ to facilitate binding of the antibodies to SP-A.

The next morning the antigen-coated plates were washed two times with PBS-Tween buffer $(200 \mu \mathrm{l} /$ well/wash). After the washes, $200 \mu \mathrm{l}$ of the content of each of the wells in the plate that contained the standards or amniotic fluid samples plus primary antibody were transferred to the antigen-coated plate. The plates were incubated for $30 \mathrm{~min}$ at room temperature, then washed two times with PBS-Tween buffer. During this step of the ELISA, any free primary antibody (i.e. that had not been bound to the SP-A in the standards or amniotic fluid samples) binds to the antigen coating the bottom of the plate. The bound primary antibody was detected by incubating the wells with a second antibody, goat anti-rabbit IgG conjugated to horseradish peroxidase (Collaborative Research, Lexington, MA), diluted 1:500. After a $2-\mathrm{h}$ incubation at room temperature, the plate was washed two times with PBS-Tween buffer. A total of $200 \mu \mathrm{l}$ of substrate $\left(0.05 \% O\right.$-diphenylamine, $0.03 \% \quad \mathrm{H}_{2} \mathrm{O}_{2}$ in distilled water) were added to each well. After a 30-min incubation at room temperature, the reaction was stopped by adding $50 \mu \mathrm{l}$ of $\mathrm{H}_{2} \mathrm{SO}_{4}(2 \mathrm{M})$ to each well, then the absorbance in each well was read at $492 \mathrm{~nm}$ using an ELISA reader (Titertek Multiskan, Eflab/oy, Helsinki, Finland). A standard curve was generated by plotting the absorbance versus the log of the SP-A concentration. The concentration of the apoprotein in the amniotic fluid samples was calculated using regression analysis. The surfactant apoprotein concentration in each amniotic fluid sample was calculated from the mean of six determinations, i.e., triplicate determinations at two different protein concentrations. The interassay variation was $10 \%$.

Amniotic fluid samples. Amniotic fluid samples were obtained from two sources. The majority of amniotic fluid samples used in this study were obtained from the clinical laboratory in which $\mathrm{L} / \mathrm{S}$ ratio and shake tests are performed to evaluate lung maturation in the fetuses of pregnant women treated at Parkland Memorial Hospital, Dallas, TX. These samples $(n=263)$ were obtained by amniocentesis performed at Parkland Hospital and had been stored at $-20^{\circ} \mathrm{C}$. Another series of amniotic fluid samples $(n=95)$ were obtained at the time of elective cesarian section. These samples, as well as those obtained by amniocentesis, were centrifuged at $600 \times g$ for $10 \mathrm{~min}$ to remove cells and debris before freezing.

Clinical data. Information concerning the mother and fetal/ neonatal outcome was available in data bases maintained by the Departments of Pediatrics and Obstetrics-Gynecology at Southwestern Medical School. Further data on the clinical outcome of 71 infants were obtained by detailed chart review. These infants were chosen because they had one or more of the following characteristics: low Apgar scores, low birth weight, maternal diabetes, or admission to the Special Care Nursery. Respiratory distress syndrome was diagnosed when an infant required more than $40 \%$ supplemental oxygen for more than $24 \mathrm{~h}$, had clinical signs of the disease, had a chest radiograph consistent with the diagnosis, and had no clinical or laboratory evidence of sepsis/ pneumonia. Transient tachypnea of the newborn was diagnosed when an infant required less than $40 \%$ oxygen for less than 2-3 days, had tachypnea without dyspnea, had a chest radiograph not diagnostic of RDS and/or pneumonia, and had no evidence of infection. Gestational age at the time of amniocentesis was calculated from the last menstrual period and was verified by a research nurse by chart review. The charts of all the diabetic and hypertensive patients were reviewed in detail to verify diagnosis and degree of diabetic control.

Data analysis. The data were anlayzed by one- or two-way analysis of variance. Newman-Keuls. multiple range test and Student's $t$ test were used to assess statistical differences between groups. Linear regression analysis was performed to assess the relationships between gestational age, surfactant apoprotein concentration, and the lecithin to sphingomyelin ratio. Data are expressed as the mean \pm SEM.

To compare the diabetic, diabetic and hypertensive, and hypertensive groups to normal pregnancies, each experimental sample was pair-matched with two controls on the basis of gestational age and sex of the fetus. The matched pairs were then compared by Student's $t$ test.

\section{RESULTS}

Characteristics of ELISA. A 2-dimensional sodium dodecyl sulfate polyacrylamide gel separation of the purified human surfactant apoprotein that was used as a standard in the ELISA is shown in Figure $1 \mathrm{~A}$. This material was purified by delipidation and affinity chromatography of lavage material obtained from a patient treated for alveolar proteinosis. To establish the specificity of the antibody used in the ELISA, $200 \mu \mathrm{g}$ of total protein present in an amniotic fluid sample obtained at term were separated by 2-dimensional gel electrophoresis, transferred to nitrocellulose paper, then probed using the rabbit antibodies directed against SP-A. The bound rabbit antibodies were detected by use of an $\left[{ }^{125} \mathrm{I}\right]$-goat anti-rabbit IgG (21). As illustrated in Figure $1 B$, the rabbit antibodies recognize SP-A in amniotic fluid. The streak at about $65 \mathrm{kDa}$ is an artifact of the blotting procedure.

A typical standard curve for the surfactant apoprotein ELISA is shown in Figure 2. The assay was linear from about 10 to 500 $\mathrm{ng} / \mathrm{ml}$. In a preliminary experiment, amniotic fluid samples were obtained by amniocentesis from a pregnancy at $16 \mathrm{wk}$ of gestation and from a term gestation pregnancy. As shown in Figure 2 , there was no immunoreactive material in the 16 -wk amniotic fluid sample when assayed at several protein concentrations. The immunoreactive material in the term amniotic fluid sample, however, showed parallelism with the surfactant apoprotein standard over a wide range of protein concentrations. 


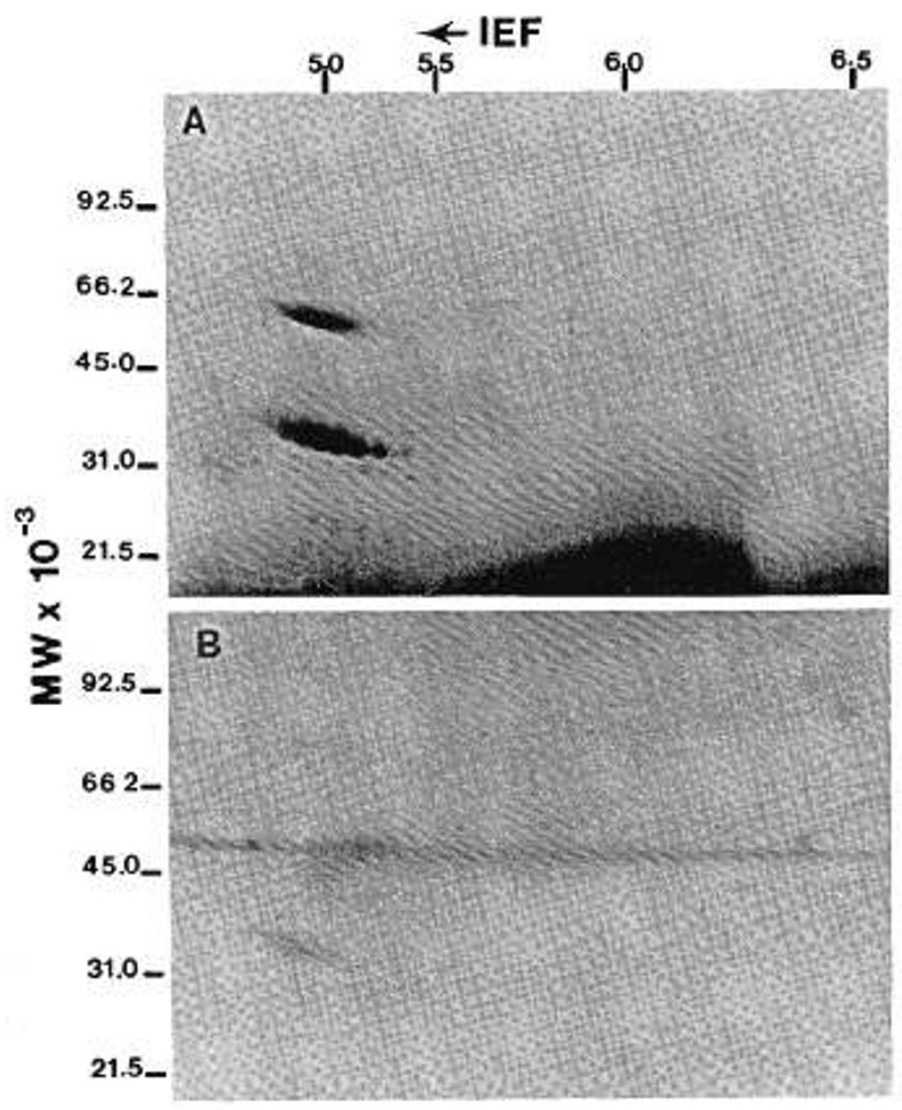

Fig. 1. Characterization of the surfactant apoprotein standard and antibodies used in the ELISA for the $35,000 \mathrm{~mol}$ wt SP-A. $A$, Coomassieblue stained, two-dimensional sodium dodceyl sulfate polyacrylamide gel separation of surfactant apoprotein purified from lavage fluid obtained from a patient treated for alveolar proteinosis. This material was used to coat the microtiter plates and as a standard. Most of the proteins present in the preparation are members of the $35,000 \mathrm{~mol} w \mathrm{w}$ surfactant apoprotein family. The proteins that migrate at about $65 \mathrm{kDa}$ are aggregates of the SP-A family of proteins. $B$, immunoblot of a twodimensional sodium dodecyl sulfate polyacrylamide gel separation of term amniotic fluid proteins. The rabbit antibodies used in the ELISA recognize the SP-A family. The streak at about $65 \mathrm{kDa}$ is an artifact of the blotting procedure.

Concentration of surfactant apoprotein in normal pregnancies. The concentration of surfactant apoprotein in amniotic fluid increased as a function of gestational age (Fig. 3). An increase in the concentration of the surfactant apoprotein in amniotic fluid was first observed at about $32 \mathrm{wk}$ of gestation. There was a great deal of variation in individual values; when grouped into 1- or 2-wk intervals, however, the observed increase was significant as assessed by ANOVA. A similar increase in the surfactant apoprotein concentration was observed irrespective of whether the data were expressed per mg protein $(p<0.05$ by ANOVA, Fig. $3 A$ ) or per ml of amniotic fluid ( $p<0.05$ by ANOVA, Fig. $3 B$ ). The concentration of total protein in the amniotic fluid samples used in this study declined as a function of gestational age until 32-34 wk of gestation after which it remained relatively constant at $3.5 \mu \mathrm{g} / \mu \mathrm{l}$ (Fig. 4). Thus, at the time in gestation when the surfactant apoprotein concentration in amniotic fluid is increasing, the total protein concentration in amniotic fluid is relatively constant. The surfactant apoprotein concentration also was measured in eight amniotic fluid samples obtained at 42-43 wk of gestation. The variance in these samples was particularly high, i.e., a mean of $37.3 \pm 14.7 \mu \mathrm{g}$ surfactant apoprotein $/ \mathrm{ml}$ amniotic fluid.

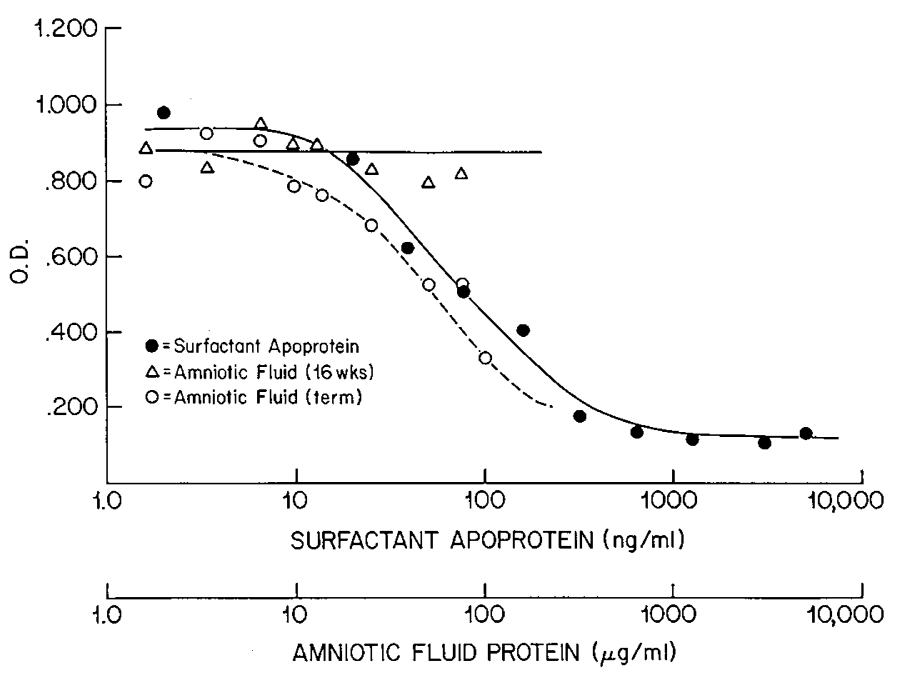

Fig. 2. Standard curve of the SP-A ELISA. The standard curve was linear from about 10 to $500 \mathrm{ng} / \mathrm{ml}$. Amniotic fluid obtained at $16 \mathrm{wk}$ gestation did not cross-react in the ELISA at several different protein concentrations. Amniotic fluid obtained at term cross reacted in the ELISA and showed parallelism with the standard over a wide range of protein concentrations.

There is considerable evidence that lung maturation is delayed in male fetuses when compared to female fetuses (27). Therefore, we grouped data concerning the concentration of amniotic fluid SP-A according to sex within 2-wk intervals (Fig. 5). Although the levels of SP-A rose with increasing gestational age, there was no significant difference in the surfactant apoprotein concentration in male compared with female fetuses at any gestational age as determined by two-way ANOVA.

Comparison of surfactant apoprotein concentration with other indices of fetal lung maturation. The shake-test results of 214 amniotic fluid samples were available for analysis. The surfactant apoprotein concentration increased as a function of gestational age in the shake-test positive amniotic fluid samples $(p<0.05$, ANOVA, $n=93$ ) (Fig. 6). In the shake-test negative amniotic fluid samples $(n=121)$, however, the surfactant apoprotein concentration remained at a relatively constant low value at every gestational age examined (Fig. 6). The difference between the surfactant apoprotein concentration in shake-test negative and shake-test positive samples was significant by two-way ANOVA $(p<0.05)$. Similar results were obtained when the data were expressed per $\mathrm{ml}$ amniotic fluid.

The L/S ratios from 145 amniotic fluid samples also were available for analysis. By linear regression analysis, a significant positive correlation was found between the L/S ratio and SP-A concentration in amniotic fluid when expressed per ml amniotic fluid or per mg amniotic fluid protein $(p<0.05, r=0.22)$ (Fig. 7). A higher degree of correlation was obtained when the log of the $\mathrm{L} / \mathrm{S}$ ratio and $\log$ of the SP-A concentrations were analyzed $(p<0.001, r=0.44)$.

Surfactant apoprotein concentration in amniotic fluid obtained from diabetic pregnancies. Amniotic fluid samples were available from 29 pregnant diabetic women, nine of whom were also hypertensive. We also determined the concentration of SP-A in amniotic fluid from 10 hypertensive women. The mean gestational age in the three groups and their matched controls were not different from each other (Table 1). The mean birth weight of the diabetic group was significantly greater than the mean birth weight of its matched control group. The mean birth weights of the other two groups and their matched controls were not different from each other. The mean $\mathrm{L} / \mathrm{S}$ ratios in the three groups were not different from their matched control groups or from each other. 


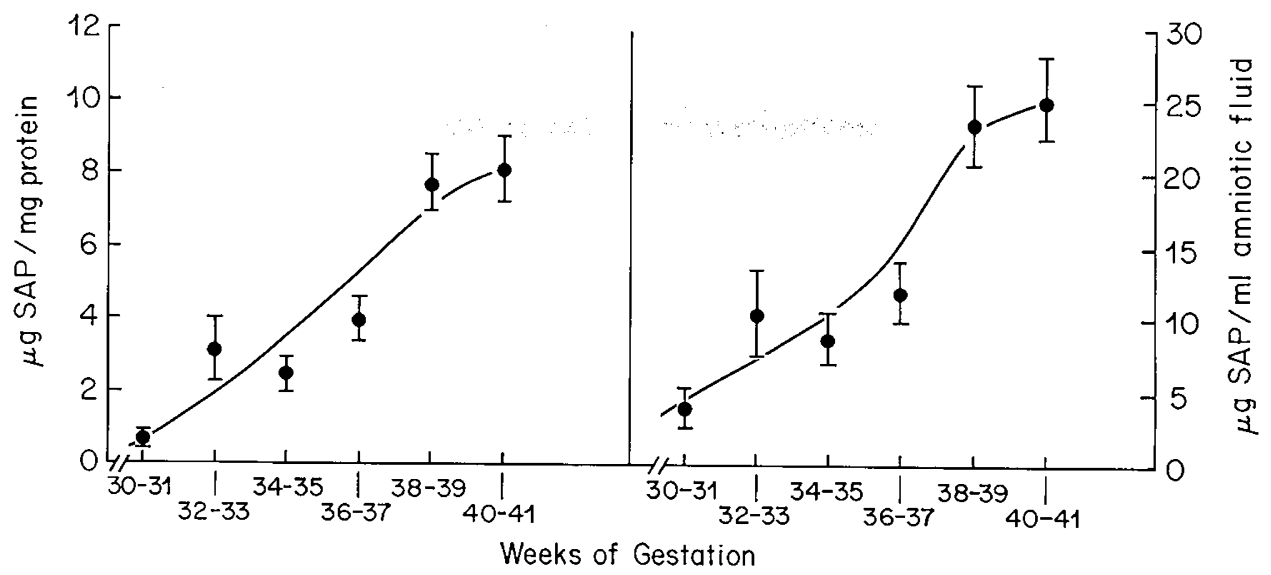

Fig. 3. Surfactant apoprotein concentration in amniotic fluid as a function of gestational age. The data were grouped into 2 -wk intervals for analysis and are expressed as the mean \pm SEM. The increase in surfactant apoprotein concentration, expressed per ml amniotic fluid or per mg amniotic fluid protein, was significant by ANOVA $(p<0.05)$. $A$, surfactant apoprotein concentration in amniotic fluid expressed per mg amniotic fluid protein. $B$, surfactant apoprotein concentration in amniotic fluid expressed per $\mathrm{ml}$ amniotic fluid volume.

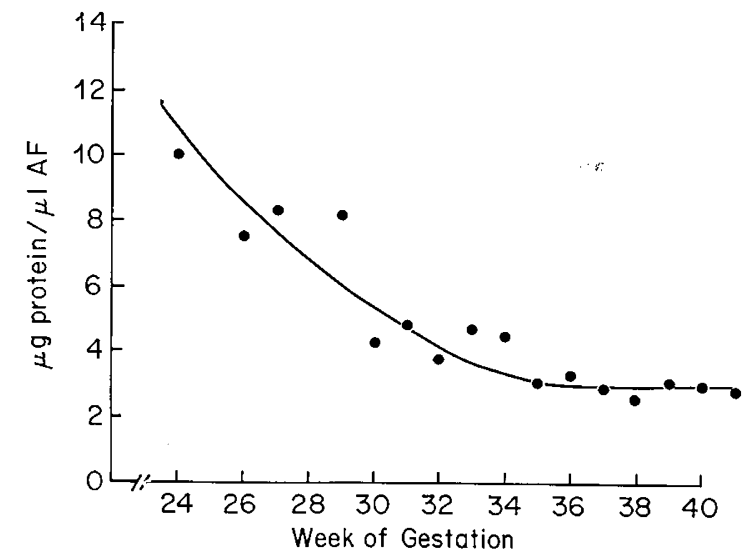

Fig. 4. Amniotic fluid total protein concentration as a function of gestational age. The data are expressed as the mean at each week of gestation.

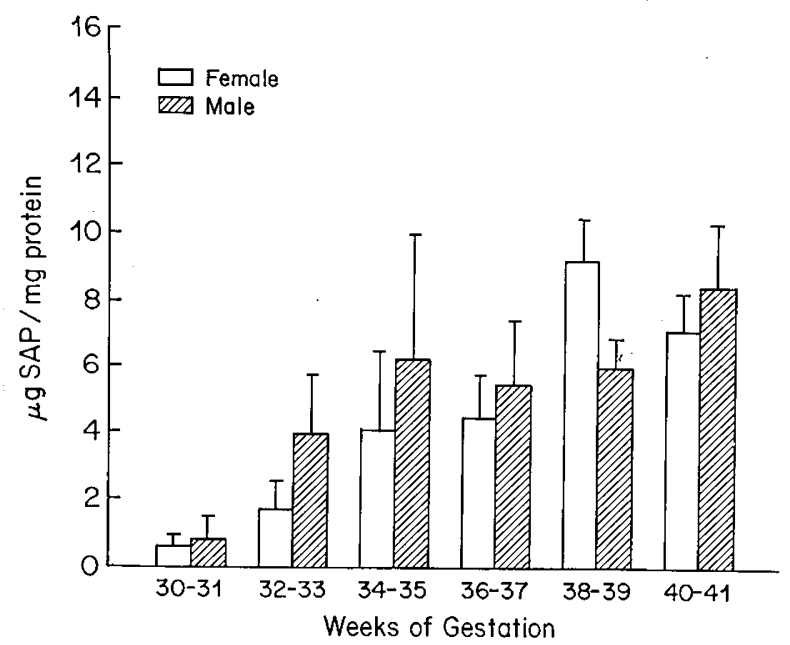

Fig. 5. Surfactant apoprotein concentration in amniotic fluid of female and male fetuses. The data are expressed as the mean $\pm \mathrm{SE}$ at each 2 -wk interval. There was no significant difference in male versus female fetuses as determined by ANOVA.

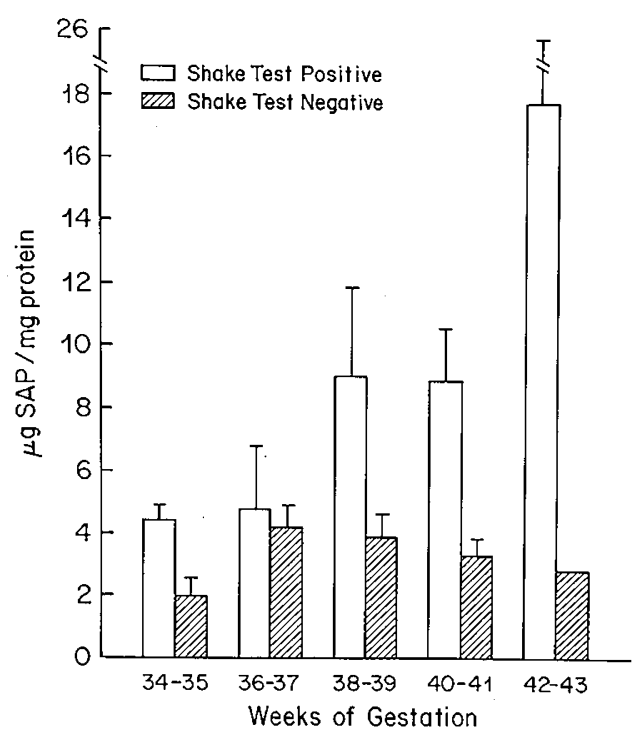

Fig. 6. Surfactant apoprotein concentration in shake test positive and negative amniotic fluid samples. The data are expressed as the mean and $1 \mathrm{SE}$ at each 2-wk interval. There was no significant increase in surfactant apoprotein concentration in shake test negative amniotic fluid samples as a function of gestational age. In contrast, the surfactant apoprotein concentration in shake test positive amniotic fluid samples increased as a function of gestational age ( $p<0.05$ by ANOVA).

The amniotic fluid SP-A concentration in diabetic, normotensive women was decreased when compared to that in a matched control group of nondiabetic women $(p<0.05$, Student's $t$ test $)$ (Fig. 8). Although the SP-A concentration in the nine diabetic, hypertensive women was not statistically different from that in a matched control group (Fig. 8), the probability was equal to 0.061 ; with the addition of more values this difference may approach significance. The SP-A concentration in the hypertensive group tended to be higher than in the matched control group, however, the difference was not significant $(p<0.22)$ (Fig. 8).

The relationship between the surfactant apoprotein concentration and the L/S ratio in the amniotic fluid samples obtained from pregnancies complicated by diabetes was analyzed using linear regression. A significant correlation between the log of the $\mathrm{L} / \mathrm{S}$ ratio and the log of the SP-A concentration was observed ( $p$ 


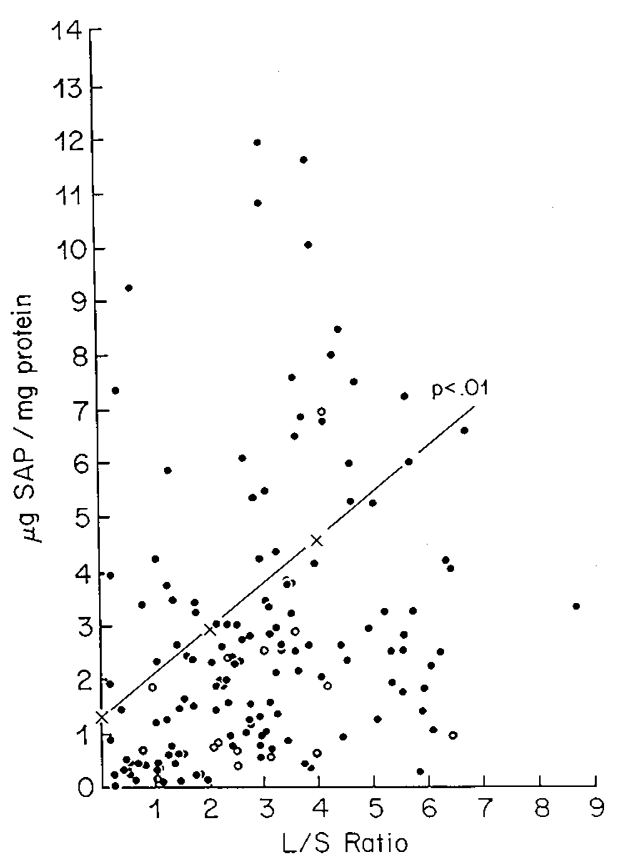

Fig. 7. The relationship between the $\mathrm{L} / \mathrm{S}$ ratio and $\mu \mathrm{g}$ surfactant apoprotein per $\mathrm{mg}$ protein in amniotic fluid samples $(n=145)$. Each point represents data from one amniotic fluid sample. Data from nondiabetics are represented by closed circles and data from diabetics are represented by open circles. Data from 11 amniotic fluid samples from nondiabetic pregnancies are not depicted because they fell outside the range of values presented in the graph. The surfactant apoprotein concentration and the L/S ratio were linearly correlated ( $p<0.01)$; [SP-A] $=1.38+(0.671) \mathrm{L} / \mathrm{S}$ ratio, in samples obtained from nondiabetic pregnancies.

Table 1. Characterization of study groups and matched controls

\begin{tabular}{|c|c|c|c|c|}
\hline \multirow[b]{2}{*}{ Condition } & \multirow[b]{2}{*}{$n$} & \multicolumn{3}{|c|}{ Mean \pm SD } \\
\hline & & $\begin{array}{c}\text { Gestational } \\
\text { age }\end{array}$ & Birth wt & $\mathrm{L} / \mathrm{S}$ ratio \\
\hline Diabetes & 20 & $37.6 \pm 1.2$ & $3663 \pm 627^{*}$ & $2.88 \pm 1.47$ \\
\hline Control & 40 & $37.6 \pm 1.2$ & $3228 \pm 357$ & $3.05 \pm 1.73$ \\
\hline $\begin{array}{l}\text { Diabetes + hyper- } \\
\text { tension }\end{array}$ & 9 & $36.4 \pm 2.7$ & $2929 \pm 1155$ & $3.41 \pm 1.62$ \\
\hline Control & 18 & $36.6 \pm 2.3$ & $2943 \pm 449$ & $2.92 \pm 2.18$ \\
\hline Hypertension & 10 & $36.6 \pm 2.3$ & $2769 \pm 816$ & $3.49 \pm 2.16$ \\
\hline Control & 20 & $36.8 \pm 2.0$ & $2979 \pm 559$ & $3.26 \pm 1.74$ \\
\hline
\end{tabular}

* Different from matched control group, $p<0.05$.

$<0.05, r=0.60$ ). Furthermore, the slope of the regression line was lower and significantly different from the slope of regression line determined for amniotic fluid samples obtained from normal pregnancies (Fig. 7). Thus, at the same L/S ratio, a lower concentration of amniotic fluid SP-A is found in the diabetic woman as compared to that in a nondiabetic woman. The total protein concentration in amniotic fluid samples obtained from diabetic women was not statistically different from that in nondiabetic women when grouped according to gestational age (data not shown). When the charts of the infants of diabetic women were reviewed $(n=29)$, there were no cases of RDS. Moreover, in only one infant did transient tachypnea occur, a 4030-g term male who also was large for gestational age.

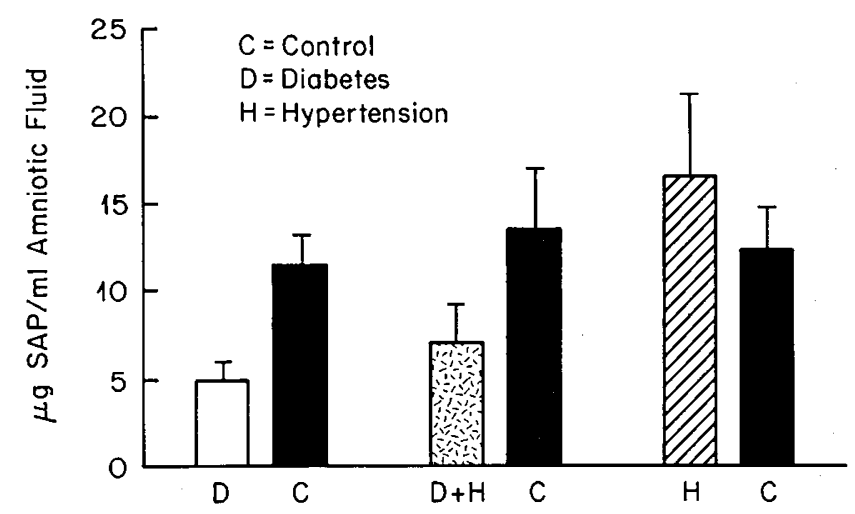

Fig. 8. Surfactant apoprotein concentration in amniotic fluid samples obtained from diabetic pregnancies, diabetics with hypertension, hypertensive pregnancies, and in matched control pregnancies. There was a statistically significant difference ( $p<0.05$, Student's $t$ test) between the diabetic group and its matched control group.

\section{DISCUSSION}

SP-A is the most abundant protein present in delipidated lamellar bodies purified from human fetal lung explants maintained in vitro (21). It is also present in high concentrations in delipidated surfactant obtained from patients treated for alveolar proteinosis and in delipidated surfactant obtained from the washes of cadaveric human lungs $(21,24)$. Thus, there is abundant evidence that SP-A is an integral component of lamellar bodies, the intracellular storage form of surfactant, and of secreted alveolar surfactant. It is not surprising, therefore, that the amniotic fluid concentration of SP-A increases as a function of gestational age (5-9). The temporal pattern of the increase in amniotic fluid SP-A observed in our study is comparable to that reported by McMahan et al. (9) and Kuroki et al. (7), although we detected somewhat higher concentrations of SP-A in amniotic fluid than did these investigators. The purity of our reference preparation was evaluated by 2-dimensional gel electrophoresis and its protein concentration was assessed by repeated protein measurements throughout the study. We also first detected an increase in the SP-A amniotic fluid concentration at about 32$33 \mathrm{wk}$ of gestation, somewhat earlier than is apparent from the data presented by McMahan et al. (9) and Kuroki et al. (7), yet similar to the data reported by Shelley et al. (6). The temporal patterns of the increase in amniotic fluid surfactant apoprotein concentration in the present study were similar when expressed per $\mathrm{ml}$ or per mg protein. Inasmuch as the amniotic fluid protein concentration remains relatively constant from $32 \mathrm{wk}$ to term, the SP-A data from 32 wk to term appear to be valid regardless of amniotic fluid volume. It is known that the amniotic fluid volume in the human decreases during the last $10 \mathrm{wk}$ of gestation (29). This may account, in part, for the slightly steeper rate of SP-A increase observed after 30-32 wk of gestation when expressed per ml amniotic fluid, although as pointed out by Nelson and Nelson (30), changes in amniotic fluid volume from 30-39 wk of gestation have minor effects on surfactant concentration measurements.

It has been reported by many investigators that male fetuses are at an increased risk to develop RDS (27). Torday et al. (31) have observed a difference in the $\mathrm{L} / \mathrm{S}$ ratios in amniotic fluid of male versus female fetuses when expressed as a function of gestational age. In addition, experimental evidence has been presented that is suggestive that the androgen, dihydrotestosterone, inhibits fetal lung type II cell maturation, especially with respect to phospholipid metabolism (32). We did not find a difference in SP-A concentration of male compared with female fetuses. This may be due to an inadequate number of samples in 
our analysis; or alternatively, SP-A may not be regulated differently in male and female fetuses. We have observed in a previous study that the phospholipid and protein components of surfactant may be regulated in an independent manner in human fetal lung tissue (21).

We compared the results of the SP-A ELISA to the results of the shake-test and to the L/S ratio for many amniotic fluid samples. When the SP-A concentration was evaluated according to the results of the shake-test, a striking difference was observed. The shake-test negative amniotic fluid samples had uniformly low surfactant apoprotein concentrations, regardless of gestational age. The biochemical basis for the shake-test is not well understood (28). Our data are suggestive, however, that SP-A may be involved in the generation of a positive shake-test result, inasmuch as the surfactant apoprotein concentration was significantly greater in shake-test positive amniotic fluid samples at 35 wk of gestation and thereafter. Furthermore, SP-A is known to be involved in the formation of tubular myelin, a form of surfactant that is thought to give rise to the monolayer of surfactant which lines the aqueous lining of the alveolus (22).

We also observed a highly significant correlation between the SP-A concentration and the L/S ratio. Katyal et al. (8) and Shelley et al. (6) have observed a similar correlation, as well as a correlation of SP-A concentration with amniotic fluid phosphatidylglycerol concentration.

In the present study, we found a significantly lower concentration of SP-A in 20 amniotic fluid samples obtained from pregnancies complicated by diabetes alone when compared to the SP-A concentration in amniotic fluid obtained from matched, nondiabetic pregnancies. Katyal et al. (8) have reported similar results using data from only four diabetic pregnancies. Recently, however, McMahan et al. (9) have reported that the SP-A concentration in amniotic fluid obtained from 30 pregnancies of diabetic women was not different from that in matched pregnant, nondiabetic women. The reasons for the discrepancy between the data of McMahan et al. (9) and our own data are not clear. The pair-matched samples in the study of McMahan et al. (9) ranged from 30-43 wk of gestation, a group that includes the extremes of the SP-A concentration in amniotic fluid. The range of gestational ages in our diabetic group was from 36-40 wk. In addition, McMahan et al. (9) stress that the diabetic women in their study were very well controlled with respect to glucose levels. Thus, it is possible that the fetuses of the diabetic women in the study of McMahan et al. (9) were not hyperinsulinemic or were less hyperinsulinemic than the fetuses of the women included in our study. Blood glucose control in the diabetic patients included in this study was variable and overall control may be considered as fair by many (33). The majority of our patients were maintained on insulin, using both short- and longacting insulin, as well as dietary control. Moreover, more than $40 \%$ of our patients were diagnosed during the third trimester of pregnancy and had only short-term attempts at control of blood glucose.

We observed no difference between the mean $\mathrm{L} / \mathrm{S}$ ratios of amniotic fluids obtained from diabetic and matched nondiabetic women, results in agreement with several studies $(9,13)$. Interestingly, in our previous studies we have never observed an inhibitory effect of insulin, when added alone, on the rate of surfactant phospholipid synthesis and lamellar body phosphatidylglycerol content in human fetal lung explants maintained in vitro. In fact, we have consistently observed a stimulatory effect of insulin, in combination with cortisol or cortisol plus prolactin, on phospholipid synthesis and lamellar body phosphatidylglycerol content. Thus, the data in the present study are in agreement with our previous in vitro findings that the deleterious effects of insulin on surfactant metabolism may be restricted to effects on the apoprotein component of surfactant and not on the phospholipid components.

None of the infants of diabetics included in our study devel- oped RDS. This may reflect the small number of infants studied and/or the age at which they were delivered. Therefore, it was not possible to evaluate the predictive value of the SP-A concentration in amniotic fluid with respect to the incidence of RDS in this population. In addition, because diabetes is a heterogeneous disease with several subgroups, it would be important to evaluate the SP-A concentration in amniotic fluid as a function of the severity of the maternal diabetes as well as the association with hypertension. A total of 14 of the 20 diabetics included in our study were gestational diabetics, i.e. type A according to White's classification whereas four were type B and two were type C. Although the SP-A concentration was decreased in all three subgroups, the greatest inhibitory effect observed was in the type A subgroup. Finally, nine of the diabetic women had hypertension; interestingly their SP-A concentration was not different from their matched nondiabetic controls.

In conclusion, although our results demonstrate that the SP-A concentration is decreased in amniotic fluid from diabetic women after $36 \mathrm{wk}$ of gestation, its relationship to the occurrence of RDS is unclear, necessitating the accumulation and study of larger populations.

Acknowledgements. The authors thank Mr. Bob Truby for performing the L/S ratio and shake-tests, Ms. Susan Cutrar, R.N. for review of patient data, Dr. Joan Reisch for advice concerning the statistical analysis of the data, and Ms. Dolly Tutton for editorial assistance. The help and encouragement provided by Dr. Paul MacDonald and Dr. Linette Casey during the course of this study is also gratefully acknowledged.

\section{REFERENCES}

1. Avery ME, Mead J 1959 Surface properties in relation to atelectasis and hyaline membrane disease. Am J Dis Child 97:517-523

2. King RJ 1982 Pulmonary surfactant. J Appl Physiol Respir Exercise Physiol $53: 1-8$

3. Lindback T, Frantz T, Skjaeraasen J, Gravens S 1974 Phospholipids in amniotic fluid I. Relationship of phospholipid concentration to gestation, maternal disease and fetal outcome. Acta Obstet Gynec Scand 53:219-226

4. Gluck L, Kulovich MV, Borer RC Jr, Anderson GG, Spellacy WN 1971 Diagnosis of the respiratory distress syndrome by amniocentesis. Am J Obstet Gynecol 109:440-445

5. King RJ, Ruch J, Gikas EG, Platzker ACG, Creasy RK 1975 Appearance of apoproteins of pulmonary surfactant in human amniotic fluid. J Appl Physiol 39:735-741

6. Shelley SA, Balis JU, Paciga JE, Knuppel RA, Ruffolo EH, Bouis PJ 1982 Surfactant 'apoproteins' in human amniotic fluid: an enzyme-linked immunoabsorbent assay for the prenatal assessment of lung maturity. Am J Obstet Gynecol 144:224-228

7. Kuroki $Y$, Takahashi $H$, Fukada $Y$, Mikawa M, Inagawa A, Fujomoto S, Akino T 1985 Two-site "simultaneous" immunoassay with monoclonal antibodies for the determination of surfactant apoprotein in human amniotic fluid. Pediatr Res 19:1017-1020

8. Katyal SL, Amenta JS, Singh G, Silverman JA 1984 Deficient lung surfactant apoprotein in amniotic fluid with mature phospholipid profile from diabetic pregnancies. Am $\mathbf{J}$ Obstet Gynecol 148:48-53

9. McMahan MJ, Mimouni F, Miodovnik M, Hull WM, Whitsett JA 1987 Surfactant associated protein (SAP-35) in amniotic fluid from diabetic and non-diabetic pregnancies. Obstet Gynecol 70:94-98

10. Whitsett JA, Notter RH, Ohning BL, Ross G, Meuth J, Weaver T, Shapiro DL, Holm BA 1986 Hydrophobic 6,000 kilodalton protein and its importance for biophysical activity in lung surfactant extracts. Pediatr Res 20:460tance

11. Hawgood S, Benson BJ, Schilling J, Damm D, Clements JA, White RT 1987 Nucleotide and amino acid sequences of pulmonary surfactant SP-18 and evidence for cooperation between SP-18 and SP28-36 in surfactant lipid absorption. Proc Natl Acad Sci USA 84:66-70

12. Ballard PL, Hawgood S, Wellenstein GA, Liley H, Benson BJ, White RT 1987 Surfactant protein of 18,000 daltons (SP-18) in human fetal lung. Pediatr Res 21:442A(abstr)

13. McMahan MJ, Hull WM, Weaver TE, Johnson JR, Whitsett JA 1987 Hydrophobic surfactant proteins (SAP-6) in human amniotic fluid: Identification and quantification by gestation. Pediatr Res 21:460A(abstr)

14. Bourbon JR, Farrell PM 1985 Fetal lung development in the diabetic pregnancy. Pediatr Res 19:253-267

15. Singh M, Mejia A, Zuspan FP 1974 Studies on human amniotic fluid phospholipids in normal, diabetic and drug abuse pregnancy. Am J Obstet Gynecol 119:623-629 
16. Cruz AC, Huhi WC, Birk SA, Spellacy WN 1976 Respiratory distress syndrome with mature lecithin/sphingomyelin ratios: Diabetes mellitus and low Apgar scores. Am J Obstet Gynecol 126:78-82

17. Obensfain SS, Adam PAJ, Ring KC, Teramo K, Raivio KO, Raiha N, Schwartz R 1970 Human fetal insulin response to sustained maternal hyperglycemia. N Engl J Med 283:566-570

18. Sosenko IR, Kitzmiller JL, Loo SW, Blix P, Rubenstein AH, Gabbay KH 1979 The infant of the diabetic mother: Correlation of increased cord c-peptide levels with macrosomia and hypoglycemia. N Engl J Med 301:859-862

19. Mendelson CR, Johnston JM, MacDonald PC, Snyder JM 1981 Multi-hormonal regulation of surfactant synthesis by human fetal lung in vitro. $\mathrm{J} \mathrm{Clin}$ Endocrinol Metab 53:307-317

20. Snyder JM, Longmuir KJ, Johnston JM, Mendelson CR 1983 Hormonal regulation of the synthesis of lamellar body phosphatidyglycerol and phosphatidylglycerol in fetal lung tissue. Endocrinology 112:1012-1018

21. Snyder JM, Mendelson CR 1987 Insulin inhibits the accumulation of the major surfactant apoprotein in human fetal lung explants maintained in vitro. Endocrinology 120:1250-1257

22. Hawgood S, Benson BJ, Hamilton RL Jr 1985 Effects of a surfactant associated protein and calcium ions on the structure and surface activity of lung surfactant lipids. Biochemistry 24:184-190

23. Hawgood S, Schleuter MA, Brown CL, Tooley WH, Buckley D, White RT, Benson BJ 1987 Effects of phospholipids, recombinant human surfactant glycoprotein and human proteins on pulmonary mechanics of premature rabbits. Pediatr Res 21:454A(abstr)

24. Phelps DS, Taeusch HW, Benson B, Hawgood S 1984 An electrophoretic and immunochemical characterization of human surfactant-associated proteins. Biochim Biophys Acta 791:226-238

25. Burnette WN 1981 "Western blotting": electrophoretic transfer of protein from sodium dodecylsulfate-polyacrylamide gels to unmodified nitrocellulose and radiographic detection with antibody and radioiodinated protein $\mathrm{A}$. Anal Biochem 112:195-201

26. Lowry OH, Rosebrough NJ, Farr AL, Randall RJ 1951 Protein measurement with the Folin phenol reagent. J Biol Chem 193:265-225

27. Torday JS, Nielsen HC 1987 The sex difference in fetal lung surfactant production. Exp Lung Res 12:1-19

28. Clements JA, Platzker DF, Tierney DF, Hobel CJ, Creasy RK, Margolis AJ, Thibeault DW, Tooley WH, Oh W 1972 Assessment of the risk of respiratory distress syndrome by a rapid test for surfactant in amniotic fluid. $\mathrm{N}$ Engl $\mathrm{J}$ Med 286:1077-1081

29. Queenan JT, Thompson W, Whitfield CR, Shaw SI 1972 Amniotic fluid volumes in normal pregnancies. Am J Obstet Gynecol 114:34-38

30. Nelson GH, Nelson SJ 1985 Theoretical effects of amniotic fluid volume changes on surfactant concentration measurements. Am J Obstet Gynecol $152 \cdot 870-878$

31. Torday JS, Nielsen HC, Fencl M de M, Avery ME 1981 Sex differences in fetal lung maturation. Am Rev Resp Dis 123:205-208

32. Nielsen HC, Zinman HM, Torday JS 1982 Dihydrotestosterone inhibits fetal rabbit pulmonary surfactant production. J Clin Invest 69:611-614

33. Leveno KJ, Hauth JC, Gilstrap LC, Whalley PJ 1979 Appraisal of "rigid" blood glucose control during pregnancy in the overtly diabetic woman. Am J Obstet Gynecol 135:853-859 